\title{
Base-Catalyzed Formation of Imidazole Derivatives
}

\author{
A. N. Vasiliev ${ }^{1}$, A. F. López ${ }^{1}$ and A. J. Mocchi ${ }^{2}$ \\ ${ }^{1} \mathrm{CITeQ}$, Facultad Córdoba, Universidad Tecnológica Nacional, Córdoba, Argentina \\ Tel./Fax: 54-351-4690-585, E-mail: vasiliev@sa.frc.utn.edu.ar \\ ${ }^{2}$ Tecnomyl SRL, Parque Industrial Avay, Villeta, Paraguay \\ Tel./Fax: 595-21-660-716, E-mail: tecnomyl@pla.net.py \\ * Author to whom correspondence should be addressed.
}

\section{Introduction}

Many 2-(2'-imidazolin-2'-yl)-3-carboxypyridines possess bioactive properties that caused their use in agriculture as herbicides and defoliants [1]. Their activity is based on inhibition of acetohydroxy acid synthesis, reducing level of valine, leucine and isoleucine to disruption of protein and DNA synthesis. Known methods of their synthesis are based on multistep processes and result in low yield of aiming products. The first of them developed by Los with co-workers starts from substitutes diethyl pyridinedicarboxylates which were hydrolized to correspondent diacids, then dehydrated to anhydrides, treated by and 2-amino-2,3-dimethylbutiramide, and finally cyclized to desired products [2]. Another method includes oxidative condensation of 2-methylnicotinic acid with and 2-amino-2,3dimethylbutiramide in the presence of elementary sulfur [3]. Due to their disadvantages, a development of simple and effective method of these compounds preparation is actual. In the present work a reaction of one-step formation of imidazoline ring is studied.

\section{Results and Discussion}

The reaction proceeds readily at heating and the final product precipitates as sodium salt. It takes place in accordance with suggested mechanism (Scheme). Firstly, N-substituted imide of dicarboxylic acid is forming. This intermediate undergoes an intramolecular condensation of one of carbonyl groups at the pyridine ring with amide group of $\mathrm{N}$-substituent. Finally, the hydrolysis of amide bond occurs. Surprisengly this reaction occurs selectively to 2-position of pyridinic ring while 3-(2'-imidazolin-2'yl)-pyridine was not detected. This method was applied to ethyl pyridine-2,3-dicarboxylates with (or without) alkyl substituents in pyridinic ring.

\section{Experimental}

Synthesis of 5-ethyl-2-(2'-imidazolin-2'-yl)-pyridine-3-carboxylic acid

To solution of diethyl ester of 5-ethylpyridine-2,3-dicarboxylic acid (2,51 g, 0,01 mol) and 2- 
amino-2,3-dimethylbutiramide $(1,30 \mathrm{~g}, 0,01 \mathrm{~mol})$ in $50 \mathrm{~mL}$ of dry toluene sodium metoxide $(1,08 \mathrm{~g}$, $0,02 \mathrm{~mol}$ ) was added during $1 \mathrm{~h}$ at intensive stirring. The reactional mixture was refluxed for $1 \mathrm{~h}$, cooled and white precipitate was filtered, washed by toluene, and dried on air. The yield of sodium salt of 5-ethyl-2-(2'-imidazolin-2'-yl)-pyridine-3-carboxylic acid was 2,39 g. The product was quantitatively converted into acidic form by dissolving in water and acidification to $\mathrm{pH}=3$. Aiming compound was filtered, washed by water and dried at ambient temperature overnight. Yield $2.21 \mathrm{~g}$ (76.5\%), m.p. $172-173^{\circ} \mathrm{C}$.

\section{Spectral data}

IR (Jasco FT/IR-5300, pellets with KBr) cm ${ }^{-1}$ : 1047, 1398, 1464, 1649, 1689, 1746; UV (Jasco UV/VIS-7800, acetonitrile) nm: 253.

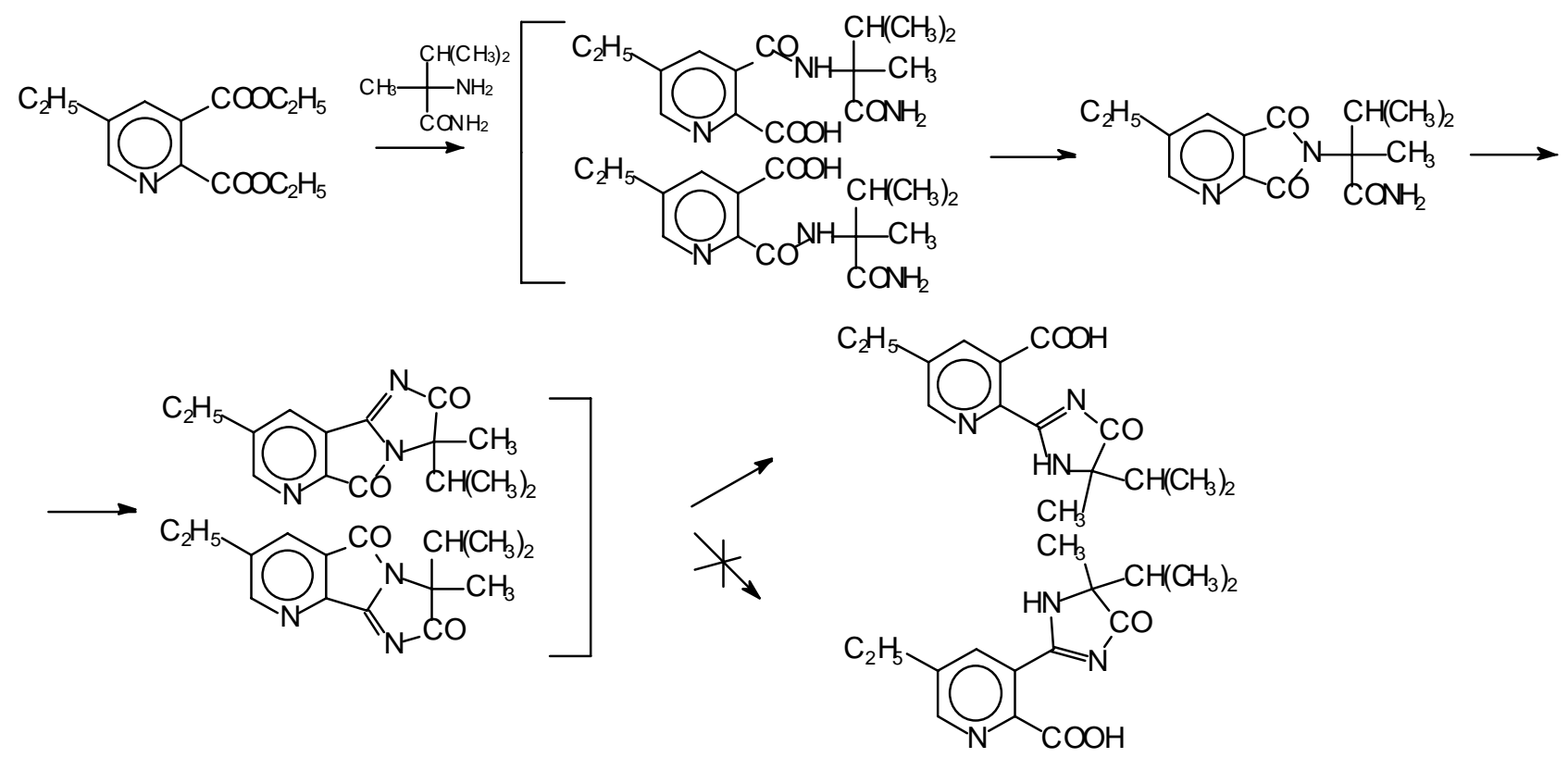

Acknowledgements: The authors wish to thank Geol. J. Fernández for his assistance in spectral analysis and Prof. E. R. Herrero for helpful discussion.

\section{References and Notes}

1. Ladner, D. W. Recent Studies of Imidazolinone Herbicides and relative Compounds, In Chemistry of Plant Protection, v.10; Stelle, J., Ed.; Springer-Verlag: Berlin-Heidelberg, 1994; p. 83-118.

2. Los, M. 2-(2-imidazolin-2-yl)-pyridines and quinolines and use of said compounds as herbicide agents, Pat. USA 4798619, publ. 17.01.89.

3. Wepplo, P.J. Process for the preparation of pyridyl and quinolyl imidazolinones, Pat. USA 4474962, publ. 02.10.84. 